\title{
The acute impact of ethanol on glucose, insulin, triacylglycerol, and free fatty acid responses and insulin sensitivity in type 2 diabetes
}

\author{
BY CHRISTIAN CHRISTIANSEN ${ }^{1}$, CLAUS THOMSEN ${ }^{1}$, OLE RASMUSSEN ${ }^{1}$, \\ CARSTEN HANSEN ${ }^{2}$ AND KJELD HERMANSEN ${ }^{1}$ \\ ${ }^{1}$ Medical Department C (University Clinic of Diabetes and Endocrinology), Aarhus Amtssygehus, \\ Aarhus University Hospital, Tage Hansensgade 2, DK-8000 Aarhus C, Denmark \\ ${ }^{2}$ Department of Forensic Toxicology, Aarhus University, Aarhus, Denmark
}

(Received 14 December 1995 - Revised 10 April 1996 - Accepted 25 April 1996)

\begin{abstract}
The aim of the present study was to evaluate the acute effect of ethanol on insulin sensitivity, and glucose, insulin, free fatty acid (FFA), and triacylglycerol responses in ten patients with non-insulin-dependent (type 2) diabetes. In the test study an oral dose of $0.66 \mathrm{~g}$ ethanol $/ \mathrm{kg}$ followed by continuous intravenous infusion of $0.1 \mathrm{~g}$ ethanol $/ \mathrm{kg}$ per $\mathrm{h}$ was given to maintain a constant ethanol level in the blood. In the control study identical volumes of oral water and intravenous saline $(9 \mathrm{~g} \mathrm{NaCl} / \mathrm{l})$ were given. After $90 \mathrm{~min}$ insulin sensitivity was determined by the hyperinsulinaemic, euglycaemic clamp technique. Ethanol caused no change in blood glucose or insulin concentrations. The FFA level was suppressed by ethanol while the triacylglycerol level was unaffected. The insulin sensitivity was not affected by ethanol. No major acute effect of ethanol on the glycaemic control in fasting type 2 diabetic patients was found in comparison with what is seen in healthy people. The present study, along with the sparse literature, indicates that the ability of ethanol to induce hypoglycaemia is attenuated or absent in diet-treated type 2 diabetes. Furthermore, we found no change in insulin sensitivity. Consequently, the risk of acute ethanol-induced aberrations in carbohydrate metabolism in diet-treated type 2 diabetes seems to be less than previously expected, when alcohol is not taken as a part of a meal.
\end{abstract}

Non-insulin-dependent diabetes mellitus: Ethanol: Insulin sensitivity

Few studies have been devoted to the effects of ethanol on glucose and lipid metabolism in non-insulin-dependent (type 2) diabetes. Moderate ethanol intake with a meal increases the insulin level (McMonagle \& Felig, 1975; Koivisto et al. 1993) while the glucose level falls slightly (McMonagle \& Felig, 1975; Gin et al. 1992) or remains unchanged (Walsh \& O'Sullivan, 1974; Koivisto et al. 1993; Christiansen et al. 1994). We previously reported that moderate ethanol intake with a small carbohydrate load $(325 \mathrm{~kJ})$ in fasting patients with type 2 diabetes induced a dose-dependent rise in the insulin level while the glucose level was unaffected (Christiansen et al. 1993).

It is well established that ethanol impairs insulin sensitivity in healthy people (Yki Järvinen \& Nikkilä, 1985; Avogaro et al. 1987; Shelmet et al. 1988; Boden et al. 1993). The ethanol-induced increase in insulin level in type 2 diabetes (Christiansen et al. 1993) could be secondary to an aggravation of the pre-existing low insulin sensitivity in type 2 diabetes.

The aim of the present study was to evaluate the acute impact of ethanol on the insulin sensitivity and glycaemic control in fasting patients with type 2 diabetes. 


\section{PATIENTS AND METHODS}

\section{Patients}

Ten patients with type 2 diabetes (three women and seven men) participated in the study. They were fully informed about the experimental nature of the study which was approved by the local ethical committee. None of the patients had a history of liver disease or ethanol abuse. They were middle-aged (54 (range 43-65) years), slightly overweight (BMI 27.0 (range $21 \cdot 5-33 \cdot 8) \mathrm{kg} / \mathrm{m}^{2}$ ) and fairly well regulated (haemoglobin $\mathrm{A}_{1 \mathrm{C}}\left(\mathrm{HbA}_{1 \mathrm{C}}\right.$ ) $7 \cdot 3$ (range $5 \cdot 3-10 \cdot 1) \%$ ). Mean duration of diabetes was 5 (range 1-15) years. No one had complications except background retinopathy. Five were treated with diet alone, three with sulphonylureas and two were treated with a combination of sulphonylureas and metformin. All patients had endogenous insulin production with postprandial serum C-peptide responses of $610-1080 \mathrm{pmol} / 1$.

\section{Experimental protocol}

The patients were studied twice in random order, with and without ethanol, with an interval of at least $4 \mathrm{~d}$ (test and control study respectively). The patients were not permitted ethanol for the last $24 \mathrm{~h}$ or any medication including antidiabetic agents for the last $12 \mathrm{~h}$ preceding the two studies. Catheters were placed in peripheral veins in the cubital fossa and on the dorsum of the contralateral hand. The antecubital line was used for infusion of glucose, insulin, and ethanol (test study) or saline $(9 \mathrm{~g} \mathrm{NaCl} / 1$; control study). The contralateral hand was placed in a heating chamber to obtain arterialized blood samples in order to determine blood glucose, serum insulin, free fatty acids (FFA), triacylglycerols, and ethanol. The samples were stored at $-20^{\circ}$ until assayed.

At 08.00 hours after an overnight fast the patients were given an oral priming dose of $0.66 \mathrm{~g}$ ethanol $/ \mathrm{kg}$ (test study) or an identical volume of tap water (control study). Continuous intravenous infusion of ethanol $(0.10 \mathrm{~g} / \mathrm{kg}$ per $\mathrm{h})$ was given throughout the test study period to establish a constant serum ethanol concentration (Fig. 1). An equal amount of saline was infused in the control study. During the first 90 min the acute responses to ethanol were measured. After $90 \mathrm{~min}$ the insulin sensitivity was measured during the continuous ethanol (test study) or saline (control study) infusion. Insulin and glucose infusions were started according to the euglycaemic, hyperinsulinaemic clamp technique, regarded as one of the most precise measures of insulin sensitivity (DeFronzo et al. 1979; Scheen et al. 1992). The serum insulin level is increased to a predetermined level by constant intravenous infusion of exogenous insulin. On the basis of prevailing blood glucose level measured every 5-10 min, a variable amount of glucose is infused to maintain euglycaemia. Provided that the endogenous glucose production is completely suppressed, the amount of glucose infused at steady state is equivalent to the amount of glucose metabolized. It is common practice to plead for steady state after $90 \mathrm{~min}$ of insulin and glucose infusion. It is questionable if steady state really exists. Doberne et al. (1981) have demonstrated that the glucose infusion rate increases for $5-6 \mathrm{~h}$ and declines thereafter. This dependency of time course does not invalidate the clamp technique but makes it mandatory that similar duration and exposure to insulin infusion is ensured. We therefore aimed for both equal infusion periods and equal exposure to exogenous insulin in both studies. Human insulin $40 \mathrm{mU} / \mathrm{m}^{2}$ per min (Actrapid, Novo Nordisk, Copenhagen, Denmark) was infused followed by $200 \mathrm{~g} / 1$ glucose.

Due to fasting, hyperglycaemia infusions were continued until stable euglycaemia was ensured. Steady-state blood glucose (test $v$. control: 5.3 (SD 0.5) v. 5.3 (SD 0.3) mmol/1, NS) was obtained after comparable time (239 (SD 42) v. 225 (SD 32) min, NS). The insulin sensitivity (M-value) was estimated during the subsequent $20 \mathrm{~min}$. 


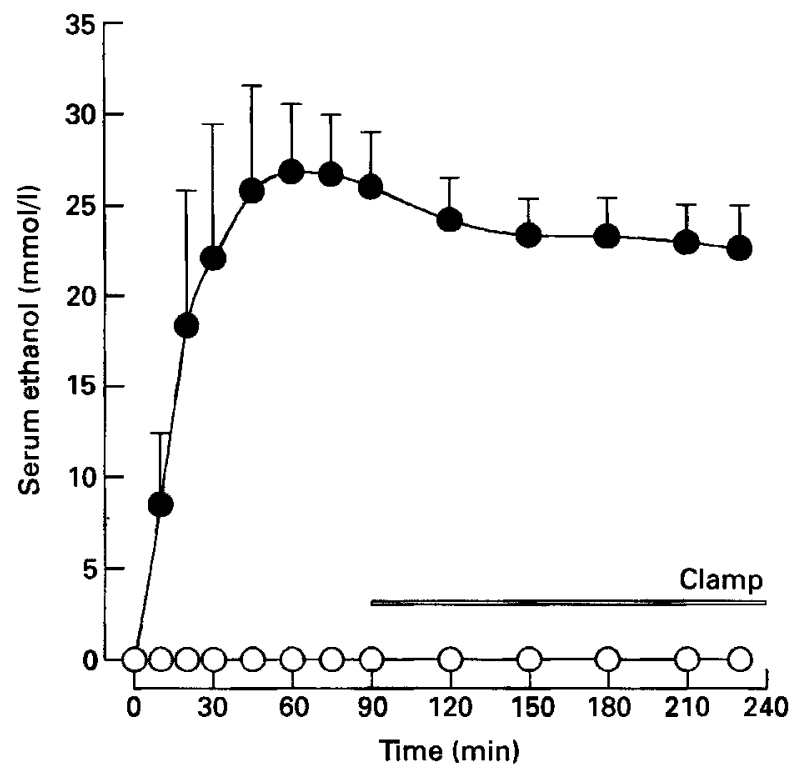

Fig. 1. Blood ethanol response to ingestion of $0.66 \mathrm{~g}$ ethanol $/ \mathrm{kg}$ followed by continuous intravenous infusion of $0.10 \mathrm{~g} / \mathrm{kg}$ per $\mathrm{h}(\mathrm{O}-\mathrm{O})$ or equivalent amounts of tap water and saline $(9 \mathrm{~g} \mathrm{NaCl} / 1 ; \mathrm{O}-\mathrm{O})$ in ten patients with type 2 diabetes. Values are means with $95 \%$ confidence intervals indicated by vertical bars.

\section{Analytical methods}

Blood glucose was measured at the bedside with a YSI glucose analyser (Yellow Springs Instruments, $\mathrm{OH}, \mathrm{USA}$ ). Serum insulin was measured by an enzyme-linked two-site immunoassay (range 5-600 pmol/l) (Andersen et al. 1993). $\mathrm{HbA}_{1 \mathrm{C}}$ was measured by ionexchange chromatography (Bio-Rad, Richmond, CA, USA; normal range 3.5-5.5\%), FFA and triacylglycerols by standard enzymic colorimetric assays using commercial kits (Waco Chemicals, Germany and Boehringer Mannheim, Mannheim, Germany). Serum ethanol was determined by GC using a headspace technique (Machata, 1975).

\section{Statistical methods}

The blood glucose, serum insulin, FFA and triacylglycerol concentrations are given as the mean values and standard deviations for the period 60-90 min when serum ethanol had reached steady state level. The insulin sensitivity (M-value) was calculated as the amount of glucose infused (mg glucose/min per $\mathrm{kg}$ ) over the last $20 \mathrm{~min}$ of the study, when insulin and glucose infusions were constant and a stable euglycaemic blood glucose level was obtained. The data for glucose, insulin, FFA, triacylglycerols, and M-value fulfilled the assumptions of normality (Kolmogorow-Smirnov test) and homogeneity of variance (Levene test) (all $P$ values $>0 \cdot 1$ ). The test and control studies were compared by paired $t$ tests. For statistically different values the standard errors of difference (SED) are given. $P$ $<0.05$ was considered statistically significant. NS denotes a non-significant result.

\section{RESULTS}

We found no significant differences in basal levels of glucose (test $v$. control: 10.8 (SD 2.4) v. 9.9 (SD 2.3) mmol/l, NS), insulin (44 (SD 22) v. 58 (SD 33) pmol/l, NS), triacylglycerols $(2 \cdot 16$ (SD 1.07) v. 2.35 (SD 1.34) $\mathrm{mmol} / \mathrm{l}$, NS) or FFA (0.69 (SD 0.21) v. 0.87 (SD 0.25) $\mathrm{mmol} / 1$, 
Table 1. Mean values of blood glucose, insulin, free fatty acids (FFA) and triacylglycerols 60-90 min after infusion of $0.66 \mathrm{~g}$ ethanol $\mathrm{kg}$ followed by continuous intravenous infusion of $0.10 \mathrm{~g} / \mathrm{kg}$ per hor equivalent amounts of tap water and saline $(9 \mathrm{~g} \mathrm{NaCl} / \mathrm{l})$ in ten patients with type 2 diabetes*

(Mean values and standard deviations)

\begin{tabular}{|c|c|c|c|c|c|}
\hline & \multicolumn{2}{|c|}{ Ethanol } & \multicolumn{2}{|c|}{ Control study } & \multirow[b]{2}{*}{$P$} \\
\hline & Mean & SD & Mean & SD & \\
\hline Glucose (mmol/l) & 11.0 & $2 \cdot 4$ & $9 \cdot 5$ & $2 \cdot 3$ & NS \\
\hline Insulin (pmol/l) & 51 & 21 & 50 & 27 & NS \\
\hline FFA $(\mathrm{mmol} / \mathrm{l})$ & $0 \cdot 36$ & 0.14 & 0.63 & 0.33 & $<0.02$ \\
\hline Triacylglycerols (mmol/l) & $2 \cdot 15$ & 1.01 & 2.05 & 0.88 & NS \\
\hline
\end{tabular}

* For details of subjects and procedures, see pp. 670-671.

NS). None of the patients had measurable ethanol in the fasting blood samples before the test or control study. Ethanol was stabilized at a steady-state serum level of 23.7 (SD 2.5) $\mathrm{mmol} / \mathrm{l}$ during the period of hyperinsulinaemic, euglycaemic clamp (Fig. 1).

The results for the initial $90 \mathrm{~min}$ before the clamp are given in Table 1. Neither serum insulin nor blood glucose levels were affected by ethanol during the 90 min ethanol infusion before the clamp period. The FFA level was depressed by ethanol (mean difference: $-0.3 \mathrm{mmol} / 1, P<0.02$, SED 0.1$)$ while the triacylglycerol level was unaffected.

The insulin sensitivity (M-value) was unaffected by ethanol administration (3.0 (SD 2.6) v. 3.5 (SD 2.9) $\mathrm{mg}$ glucose/min per $\mathrm{kg}$, NS).

\section{DISCUSSION}

Severe ethanol-induced hypoglycaemia is a well-known complication in insulin-dependent (type 1) diabetes and in healthy people. It is ascribed to the fact that intake of even small amounts of ethanol increases the NADH production which in turn impairs gluconeogenesis (Shelmet et al. 1988; Yki Järvinen et al. 1988). The risk of hypoglycaemia is more pronounced when hepatic glycogen deposits become small, e.g. during the fasting state or in malnutrition, because glycogenolysis cannot contribute to blood glucose homeostasis. Hypoglycaemia can occur at low, non-intoxicating blood ethanol levels and may occur even in occasional drinkers who have missed or delayed food intake (Marks, 1978).

No change in blood glucose was detected in the first $90 \mathrm{~min}$ of the present study. Severe hypoglycaemia after moderate ethanol intake in patients with type 2 diabetes has not been reported. Neither has late hypoglycaemia, as can be seen in healthy people 6-18 h after ethanol intake (Freinkel et al. 1965; Wallgren \& Barry, 1970; Menzel et al. 1991).

Both type 2 diabetes and obesity are associated with decreased insulin sensitivity. The tendency to become hypoglycaemic after ethanol intake seems to be reduced in obese patients. Compared with normal people, who become hypoglycaemic to ethanol after $72 \mathrm{~h}$ fasting, seventeen out of twenty-one obese patients had unaffected blood glucose levels under similar conditions (Arky et al. 1968). Interestingly, hepatic glucose output in type 2 diabetes has been reported not to decrease in response to ethanol (Puhakainen et al. 1991). The glycogen deposits are large in type 2 diabetes due to frequent episodes of hyperglycaemia resulting in increased glycogen synthesis (Clore et al. 1992; Del Prato et al. 1993). The reduced ability to dispose of glucose (as a result of impaired insulin sensitivity) 
in combination with a higher rate of glycogenolysis in type 2 diabetes (Del Prato et al. 1993) might explain why severe hypoglycaemia has not been reported in diet-treated type 2 diabetes.

In the present study we found no rise in the insulin level in response to ethanol, in contrast to our study in fasting patients with type 2 diabetes where ethanol was taken with a $325 \mathrm{~kJ}$ carbohydrate load (Christiansen et al. 1993). In the latter study a threefold increase in insulin level expressed as the area under the curve was observed in spite of an unchanged glucose level. The ability of ethanol to augment insulin levels in the presence of food has also been reported by others (Friedenberg et al. 1971; McMonagle \& Felig, 1975; Koivisto et al. 1993). The ethanol-induced rise in insulin seems to be dependent on simultaneous food intake. The observed rise in insulin in response to ethanol taken with a meal might be due to decreased insulin sensitivity (Christiansen et al. 1993). However, in the present study we found no decrease in insulin sensitivity (M-value) to ethanol during the hyperinsulinaemic, euglycaemic clamp in contrast to what has been found in normal people (Yki Järvinen \& Nikkilä, 1985; Avogaro et al. 1987; Shelmet et al. 1988; Boden et al. 1993). The reason for this is not known. The possibility exists that ethanol causes a slight extra decrease in the insulin sensitivity in type 2 diabetes which might have been overlooked due to dilution by the pre-existing, prominent insulin resistance.

The FFA level was decreased by ethanol probably due to a shift in NADH:NAD ratio and an increased level of acetate, a consequence of ethanol oxidation which directly inhibits lipolysis (Lieber et al. 1962; Crouse et al. 1968; Hjemdahl, 1976).

The triacylglycerol levels were unaffected by ethanol in the present study, although we had expected higher levels to be obtained as previously reported in healthy people (Verdy \& Gattereau, 1967; Jaillard et al. 1971; Schneider et al. 1985; Mishra et al. 1991). Large amounts of $\alpha$-glycerophosphate and acetate are produced as a result of ethanol breakdown and could be expected to give rise to increased triacylglycerol production. The fact that our patients already had high levels of triacylglycerols, as often seen in type 2 diabetes, may have concealed a minor increase in triacylglycerol levels.

The risk of ethanol-induced acute severe hypoglycaemia in diet-treated type 2 diabetes seems not to be great. It should, however, be underlined that ethanol can increase the risk of hypoglycaemia in patients with type 2 diabetes treated with insulin or sulphonylureas. Consequently, it seems reasonable for patients with type 2 diabetes, who choose to drink ethanol, not to exceed more than three beverages daily as also recommended by the British Diabetic Association (Connor \& Marks, 1985). Until further knowledge on the risk of hypoglycaemia is obtained, it seems advisable, at least for type 2 diabetic patients treated with insulin or sulphonylureas, only to drink moderate or large amounts of ethanol in addition to a meal.

In conclusion, no symptoms or signs of acute hypoglycaemia in response to a moderate amount of ethanol were seen in patients with type 2 diabetes. Unchanged glucose and insulin levels, as well as an unaffected insulin sensitivity (M-value) were found in type 2 diabetes in response to ethanol.

This work was supported by the National Board of Health (Board for Alcohol Policy), the Danish Diabetes Association, Novo Nordisk Foundation, Fonden til Lægevidenskabens Fremme, King Christian X's Foundation, and the Institute of Experimental Clinical Research, Aarhus University.

Andersen, L., Dinesen, B., Jørgensen, P. N., Poulsen, F. \& Röder, M. E. (1993). Enzyme immunoassay for intact human insulin in serum or plasma. Clinical Chemistry 39, 578-582. 
Arky, R. A., Abramson, E. A. \& Freinkel, N. (1968). Alcohol hypoglycemia. VII. Further studies on the refractoriness of obese subjects. Metabolism 17, 977-987.

Avogaro, A., Fontana, P., Valerio, A., Trevisan, R., Riccio, A., Del Prato, S., Nosadini, R., Tiengo, A. \& Crepaldi, G. (1987). Alcohol impairs insulin sensitivity in normal subjects. Diabetes Research 5, $23-27$.

Boden, G., Chen, X., DeSantis, R. A. \& Kendrick, Z. (1993). Ethanol inhibits insulin action on lipolysis and on insulin release in elderly men. American Journal of Physiology 265, E197-E202.

Christiansen, C., Thomsen, C., Rasmussen, O., Glerup, H., Bertelsen, J., Hansen, C., Ørskov, H. \& Hermansen, K. (1993). Acute effects of graded alcohol intake on glucose, insulin and FFA levels in non-insulin dependent (NIDDM) subjects. European Journal of Clinical Nutrition 47, 648-652.

Christiansen, C., Thomsen, C., Rasmussen, O., Hauerslev, C., Balle, M., Hansen, C. \& Hermansen, K. (1994). Effect of alcohol on glucose, insulin, free fatty acid and triglyceride responses to a light meal in non-irisulindependent (NIDDM) diabetic subjects. British Journal of Nutrition 71, 449-454.

Clore, J. N., Post, E. P., Bailey, D. J., Nestler, J. E. \& Blackard, W. G. (1992). Evidence for increased liver glycogen in patients with non-insulin-dependent diabetes mellitus after a 3-day fast. Journal of Clinical Endocrinology and Metabolism 74, 660-666.

Connor, H. \& Marks, V. (1985). Alcohol and diabetes. Diabetic Medicine 2, 413-416.

Crouse, J. R., Gerson, C. D., DeCarli, L. M. \& Lieber, C. S. (1968). Role of acetate in the reduction of plasma free fatty acids produced by ethanol in man. Journal of Lipid Research 9, 509-512.

DeFronzo, R. A., Tobin, J. D. \& Andres, R. (1979). The glucose clamp technique: a method for quantifying insulin secretion and resistance. American Journal of Physiology 6, E214-E223.

Del Prato, S., Bonadonna, R. C., Bonora, E., Gulli, G., Solini, A., Shank, M. \& DeFronzo, R. A. (1993). Characterisation of cellular defects of insulin action in type 2 (non-insulin-dependent) diabetes mellitus. Journal of Clinical Investigation 91, $484-494$.

Doberne, L., Greenfield, M. S., Schulz, B. \& Reaven, G. M. (1981). Enhanced glucose utilisation during prolonged glucose clamp studies. Diabetes 30, 829-835.

Freinkel, N., Arky, R. A., Singer, D. L., Cohen, A. K., Bleicher, S. J., Anderson, J. B., Silbert, C. K. \& Foster, A. E. (1965). Alcohol hypoglycemia. IV. Current concepts of pathogenesis. Diabetes 14, 350-361.

Friedenberg, R., Metz, R., Mako, M. \& Surmaczynska, B. (1971). Differential plasma insulin response to glucose and glucagon stimulation following ethanol priming. Diabetes 6, 397-403.

Gin, H., Morlat, P., Ragnaud, J. M. \& Aubertin, J. (1992). Short-term effect of red wine (consumed during meals) on insulin requirement and glucose tolerance in diabetic patients. Diabetes Care 15, 546-548.

Hjemdahl, P. (1976). Studies on the antilipolytic effect of acidosis. Acta Physiologica Scandinavica 434, Suppl., 21-27.

Jaillard, J., Sezille, G., Scherpereel, P. H. \& Fruchart, J. C. (1971). Etude clinique et expérimentale des modifications des lipides plasmatiques induites par l'alcool (Clinical and experimental studies on modifications to plasma lipids induced by ethanol). Nutrition et Métabolisme 13, 114-127.

Koivisto, V. A., Tulokas, S., Toivonen, M., Haapa, E. \& Pelkonen, R. (1993). Alcohol with a meal has no adverse effects on postprandial glucose homeostasis in diabetic patients. Diabetes Care 16, 1612-1614.

Lieber, C. S., Leevy, C. M., Stein, S. W., George, W. S., Cherrick, G. R., Abelmann, W. H. \& Davidson, C. S. (1962). Effects of ethanol on plasma free fatty acids in man. Journal of Laboratory and Clinical Medicine 59, $826-832$.

Machata, G. (1975). The advantages of automated blood alcohol determination by head space analysis. Zeitung für Rechtsmedizin 75, 229-234.

McMonagle, J. \& Felig, P. (1975). Effects of ethanol ingestion on glucose tolerance and insulin secretion in normal and diabetic subjects. Metabolism 5, 625-632.

Marks, V. (1978). Alcohol and carbohydrate metabolism. Journal of Clinical Endocrinology and Metabolism 7 , 333-349.

Menzel, R., Mentel, D. C., Brunstein, U. \& Heinke, P. (1991). Effect of moderate ethanol ingestion on overnight diabetes control and hormone secretion in type 1 diabetic patients. Diabetologia 34, A118.

Mishra, L., Le, N. A., Brown, W. V. \& Mezey, E. (1991). Effect of acute intravenous alcohol on plasma lipoproteins in man. Metabolism 40, 1128-1130.

Puhakainen, I., Koivisto, V. A. \& Yki Järvinen, H. (1991). No reduction in total hepatic glucose output by inhibition of gluconeogenesis with ethanol in NIDDM patients. Diabetes 40, 1319-1327.

Scheen, A. J., Paquot, N., Castillo, M. J. \& Lefebvre, P. J. (1992). How to measure insulin sensitivity in vivo. Diabetes Metabolism Reviews 10, 151-188.

Schneider, J., Liesenfeld, A., Mordasini, R., Schubotz, R., Zöfel, P., Kubel, F., Vandre-Plozzirzka, C. \& Kaffarnik, H. (1985). Lipoprotein fractions, lipoprotein lipase and hepatic triglyceride lipase during short-term and long-term uptake of ethanol in healthy subjects. Atherosclerosis 57, 281-291.

Shelmet, J., Reicharat, G., Skutches, C., Holdtke, R., Owen, O. \& Boden, G. (1988). Ethanol causes acute inhibition of carbohydrate, fat and protein oxidation and insulin resistance. Journal of Clinical Investigation $\mathbf{8 1}$, $1137-1145$.

Verdy, M. \& Gattereau, A. (1967). Ethanol, lipase activity, and serum-lipid level. American Journal of Clinical Nutrition 20, 997-1003. 
Wallgren, H. \& Barry, H. (1970). Actions of Alcohol, pp. 77-129. Amsterdam: Elsevier Publishing Co.

Walsh, C. H. \& O'Sullivan, D. J. (1974). Effects of moderate alcohol intake on control of diabetes. Diabetes 23, 440-442.

Yki Järvinen, H., Koivisto, V. A., Ylikahri, R. \& Taskinen, M. R. (1988). Acute effects of ethanol and acetate on glucose kinetics in normal subjects. American Journal of Physiology 254, E175-E180.

Yki Järvinen, H. \& Nikkilä, E. A. (1985). Ethanol decreases glucose utilisation in healthy man. Journal of Clinical Endocrinology and Metabolism 61, 941-945. 